EPiC Series in Engineering
Volume 3, 2018, Pages 1298-1305
HIC 2018. 13th International
Conference on Hydroinformatics

\title{
Flash flood simulations based on shallow water equations to investigate protection measures for El Gouna, Egypt
}

\author{
Ester Marafini ${ }^{1}$, Franziska Tügel $^{2}$, Ilhan Özgen ${ }^{3}$, Reinhard Hinkelmann $^{2}$ \\ and Michele La Rocca ${ }^{1}$ \\ ${ }^{1}$ Department of Engineering, Università degli Studi Roma Tre, Rome, Italy \\ ${ }^{2}$ Chair of Water Resources Management and Modeling of Hydrosystems, Technische Universität \\ Berlin, Germany \\ ${ }^{3}$ RIKEN Advanced Institute for Computational Science, Kobe, Japan. \\ estermarafini@hotmail.it, tuegel@tu-berlin.de, ilhan.oezgen@wahyd.tu-berlin.de, \\ reinhard.hinkelmann@wahyd.tu-berlin.de,michele.larocca@uniroma3.it
}

\begin{abstract}
Severe and sudden events like flash floods are considered to be one of the most hazardous environmental disasters. Therefore, predicting the whole process of flooding is fundamental to prevent urban damages. In this context, the simulation of flash floods is an important tool to analyse the flow processes in order to find solutions to the problem. In this work, a case study of the flash flood event of $9^{\text {th }}$ March 2014 in the city of El Gouna in Egypt was carried out using the Hydroinformatics Modeling System (hms), a two-dimensional (2D) shallow water model developed at the Chair of Water Resources Management and Modeling of Hydrosystems, Technische Universität Berlin. The flooding processes are simulated in great detail on unstructured grids. The aim of this work is to investigate the flow field around the settlement of the study area, when structures such as storage basins and dams are adopted as protection measures for the city. Different scenarios are analyzed to find out the most suitable one, which is able to minimize the risk during the flash flood event.
\end{abstract}

\section{Introduction}

Flash floods are a particular kind of floods characterised by extreme intensity and unpredictability. Cities without protection measures are especially vulnerable and may suffer severe infrastructural damages and casualties. Also, arid regions such as the Sahara Desert are often affected by flash floods while their impact spatially vary with respect to the local extent of the rainfall event (Tügel, Özgen, Simons, Zhao, \& Hinkelmann, 2017). The presence of dry and wide riverbeds, called wadis, lets the 
water flow from valleys to urban areas after a heavy rainfall resulting in negative consequences for those cities and their inhabitants. Thus, to prevent and possibly avoid dramatic situations, significant amount of research is carried out in the forecasting field. Here, the simulation of the flooding process is a helpful tool to predict the effects of the flash flood in a certain city. These results can be used to design suitable preemptive measures. However, the accurate forecasting of floods is very challenging. In addition, in most settlements of the Eastern Desert of Egypt there is a lack of meteorological measurements, except for few cities along the Red Sea coast and the river Nile (Hadidi, 2016).

In this work, a case study of a flood event in El Gouna, Egypt, has been carried out in order to analyze the flow field in flooding conditions and compare effects of different mitigation measures for urban areas. The simulation of the extreme event has been repeated using different kind of protection measures such as dams and storage basins, to discuss the safe scenarios adequate to mitigate the flooding.

\section{2D shallow water model}

The mathematical model adopted to represent the physical process is based on the two-dimensional shallow water equations which form a non-linear hyperbolic system of first-order partial differential equations. As a matter of fact, there is usually no analytical solution for this kind of system, thus it can be solved only numerically. In this work, the Hydroinformatics Modeling System (hms) is used for this purpose. hms is a Java-based, object-oriented software framework which has been developed at the Chair of Water Resources Management and Modeling of Hydrosystems, Technische Universität Berlin (Busse, Simons, Mieth, Hinkelmann, \& Molkenthin) (Simons, Busse, Hou, Özgen, \& Hinkelmann, A model for overland flow and associated processes within the Hydroinformatics Modelling System, 2014) (Simons, Busse, Hou, Özgen, \& Hinkelmann, HMS: Model Concepts and Numerical Methods around Shallow Water Flow within an Extendable Modeling Framework Understanding Changing Climate and Environment and Finding Solutions, Proceedings of the 10th International Conference on Hydroinformatics, 2012). The equations are solved with a cell-centered TVD MUSCL finite-volume scheme using a Harten, Lax and van Leer approximate Riemann solver with the contact wave restored (HLLC) is used (Hou, Simons, \& Hinkelmann, A new TVD method for advection simulation on 2D unstructured grids, 2013) (Özgen, Simons, Zhao, \& Hinkelmann, 2014) (Hou, Liang, Simons, \& Hinkelmann, 2013) (Murillo, García-Navarro, \& Burguete, 2009). The scheme applies explicit time discretization and its stability is restricted by the Courant-Friedrich-Lewy criterion (Simons, Busse, Hou, Özgen, \& Hinkelmann, A model for overland flow and associated processes within the Hydroinformatics Modelling System, 2014). The Courant number depends on velocity, cell size and time step and it is typically calculated for each cell. Stability is ensured if the Courant number is enforced to be lesser than 1 . In this work, a Courant number of 0.3 is chosen and the time step size is adapted accordingly. Cells are considered dry if the water depth in the cell is smaller than a fixed threshold (here: $10^{-6} \mathrm{~m}$ ).

\section{Case study}

\subsection{Study area}

El Gouna is a town located at the Red Sea coast of Egypt as shown in Figure 1. Its position in the wadi Bili makes it vulnerable to flash flood events. Moreover, it is one of the ungauged cities in that region. However, during the event of the $9^{\text {th }}$ March 2014 measurements of rainfall and runoff were taken and processed at the campus of the Technische Universität Berlin in El Gouna, and published in 
Hadidi's PhD Thesis 2016 (Hadidi, 2016). Those data are the basis for the numerical simulation of that event. In particular, the flooding was generated by a heavy rainfall which had been firstly accumulated in the mountainous area, located in the west side of the domain, and then flowed through the wadi valley until the lagoons at the sea. Furthermore, the rainfall which falls directly in the area of El Gouna also lead to inundations.

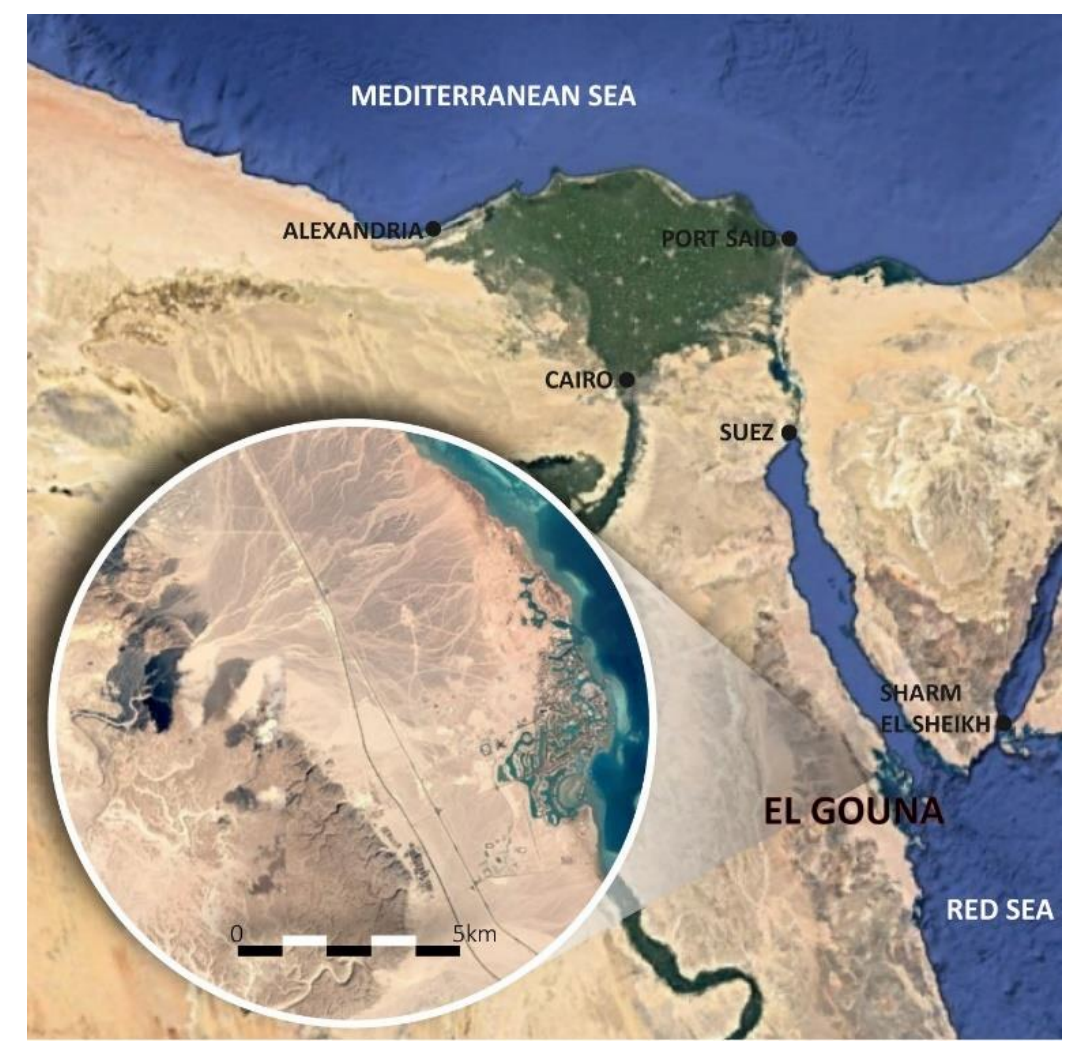

Figure 1: Study area around El Gouna, Egypt (Google Earth 2017)

\subsection{Geometry, boundary and initial conditions}

The domain chosen for the simulation in wadi Bili is illustrated in Figure 2. The dimensions of the domain are $11 \mathrm{~km}$ in $\mathrm{x}$-direction and $8 \mathrm{~km}$ in y-direction. The boundaries are open for each side of the domain. Moreover, a discharge inflow comes into the area along 30 metres on the left boundary, where the outlet of wadi Bili is located, according to the hydrograph in Figure 3 (right). Additionally, a constant rainfall over the whole domain with an intensity of $3.67 \mathrm{~mm} / \mathrm{h}$ lasting for 8 hours after the beginning of the event represents the distributed source in the mass balance equation. 


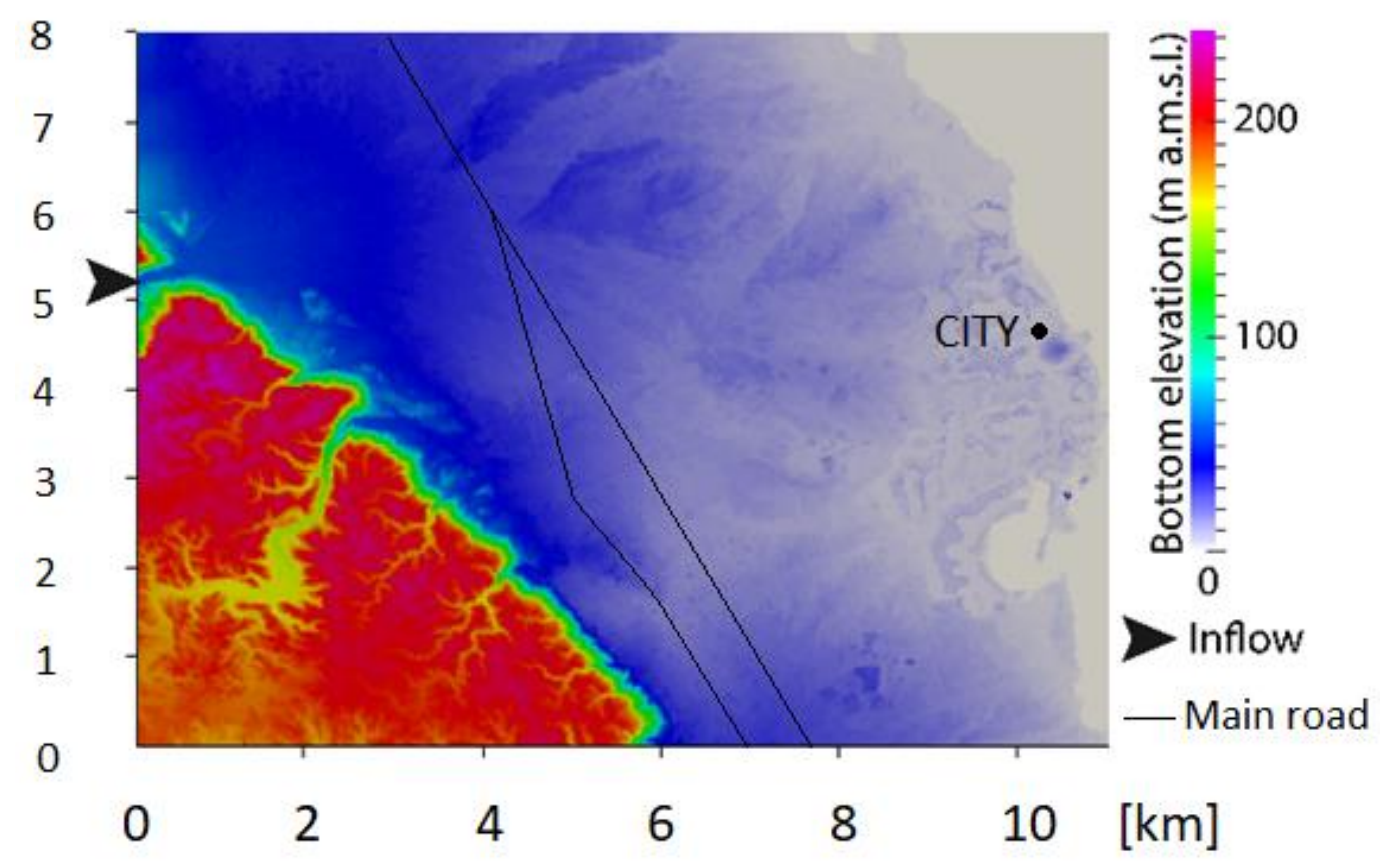

Figure 2: Digital Elevation Model (DEM) for the study area

The system is dry at the beginning of the simulation and 72 hours were simulated to see how the city is affected by the flash flood propagating through the domain, also when the rainfall event itself stopped and no additional inflow neither precipitation is entering the system. To introduce the roughness effect, the Manning's law was used with a Manning coefficient of $0.033 \mathrm{~m}^{-\frac{1}{3}} S$ representing the friction of a natural channel without vegetation.

\subsection{Grid}

An unstructured mesh, consisting of 562,086 triangular cells, is adopted to discretize the domain. Such a high number of cells is due to the fact that the length for most of the elements is 15 metres. Considering the spatial resolution of the DEM ( 30 metres), the $15 \mathrm{~m}$ cell size ensures that at least 2 cells can represent the flow path. To increase the accuracy of the results, the eastern area nearby the city was refined. Moreover, the squared and rectangular surfaces in the grid (blue lines in Figure 3) have to be accounted for in the mesh to accurately represent the implementation of protection measures in the investigated scenarios. The same mesh should be used to compare the different scenarios to prevent any impact of the grid on the results. The grid which is illustrated in Figure 3 (left) is used in this context even to simulate the flow field without any protection structures. 


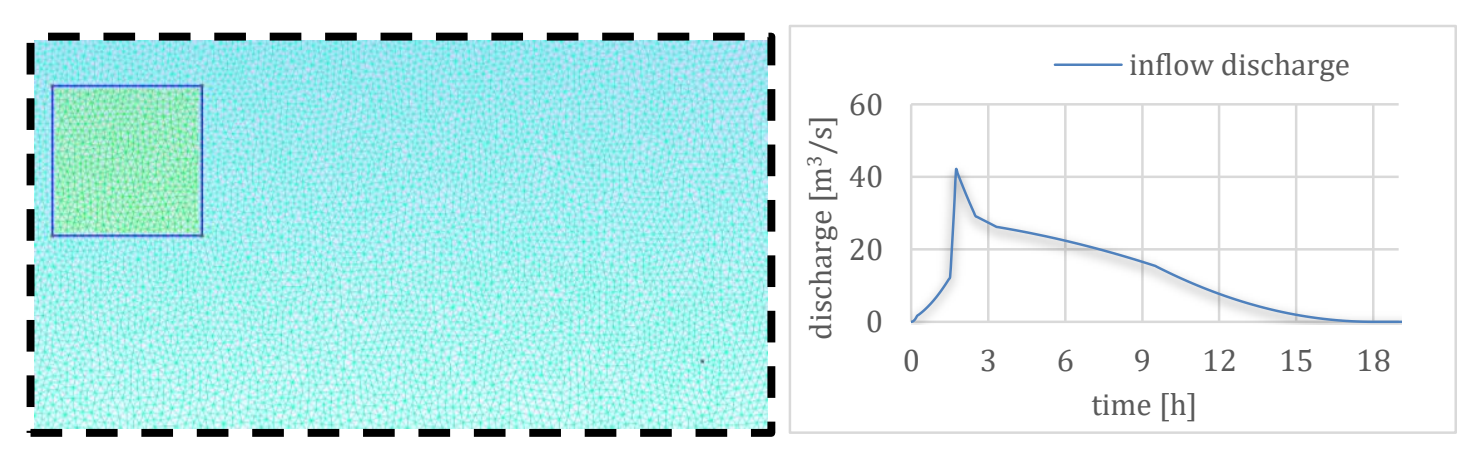

Figure 3:Unstructured grid with triangular cells (left), hydrograph for inflow discharge (right)

\subsection{Protection measures}

While the flow penetrates the domain and circulates within it, it is possible to recognize the main flow direction: from north-west to south-east. It is also necessary to observe how the spreading of the flow throughout the study area is influenced by the topography. Some critical points were chosen (see points A, B, C, D, E, F, G in Figure 4) in order to compare water depth values in the following cases:

- without protections;

- a first scenario adopting a large storage basin and a dam as protection measures;

- a second scenario with a large storage basin and two little ones as protection measures.

Taking into account the large spreading nearby the incoming of the inflow in the north-west zone, the first scenario foresees the presence of a large basin able to store all the water volume coming from the larger wadi catchment. The basin, has a capability of $2.5 \cdot 10^{6} \mathrm{~m}^{3}$, while the total volume of the inflow is less, amounting to $8.65 \cdot 10^{5} \mathrm{~m}^{3}$. Its design implies that the water in the rest of the domain is only due to the rainfall, since no overflow is observed. It presents a mild slope on the western side (5\%), to avoid steep gradients in the computation. The other protection measure together with the basin is a dam indicated in the same picture with the green line. The dam consists of an inclined barrier, which hinders the flux toward the city and also redirects it to the south, deviating it from the urban area. The dam was simplified generated by creating a hole into the grid and therefore no slope could be implemented to the inclined structure. The lack of slope on abrupt gradients could have led to possible instability problems. However, the barrier is 4 kilometres long and located between the main road and the city, far away from any buildings. Its orientation was chosen to be suitable to let the water easily flow, according to the local average slope. Unfortunately, the simulation results show clearly that some natural depressions next to the dam do not allow the flow moving toward the desired direction, but let the water accumulate in front of the structure. Therefore, it seems that such a barrier should be replaced with another kind of protection, because it does not perform in the way as it was expected to. On the other hand, the large basin is considered to accomplish its function, avoiding the solution of establishing several barriers surrounding the city. 

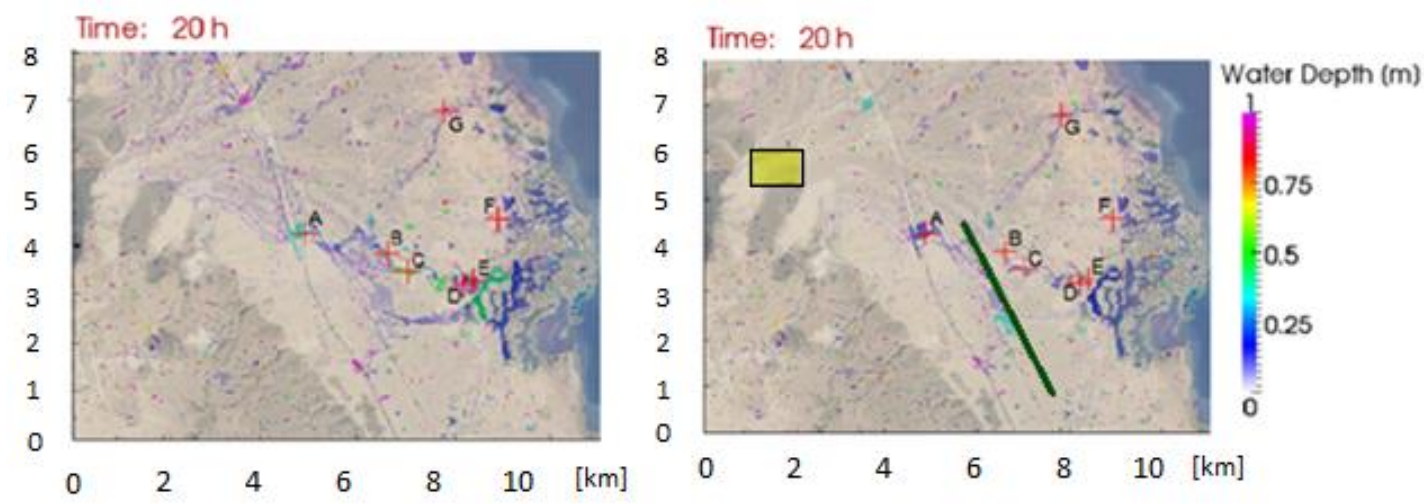

Figure 4: Water depths after 20h with no protection (left), with a large basin and a dam as protection (right)

A second scenario has been conceived in order to compare different approaches to the problem. As mentioned before, the large basin is considered to be very suitable to this situation, so it seems reasonable not to replace it with anything else. Whereas, instead of the dam it was thought to put two little basins where some natural depressions are already located. The last solution has been designed to prevent any overflow, storing the water to face eventual emergency supplying. In this context, the two little basins are indicated in Figure 5 as red and green squared shapes. This solution seems to realize a great protection for the city of El Gouna, because these kinds of mitigation measures effectively reduce water depth values nearby the urban area by storing the water as expected. In particular, comparing water depths in the case without protections to the first and the second scenario (Figure 6), the last solution has been proven to reach the lowest values undershooting 25 centimetres.
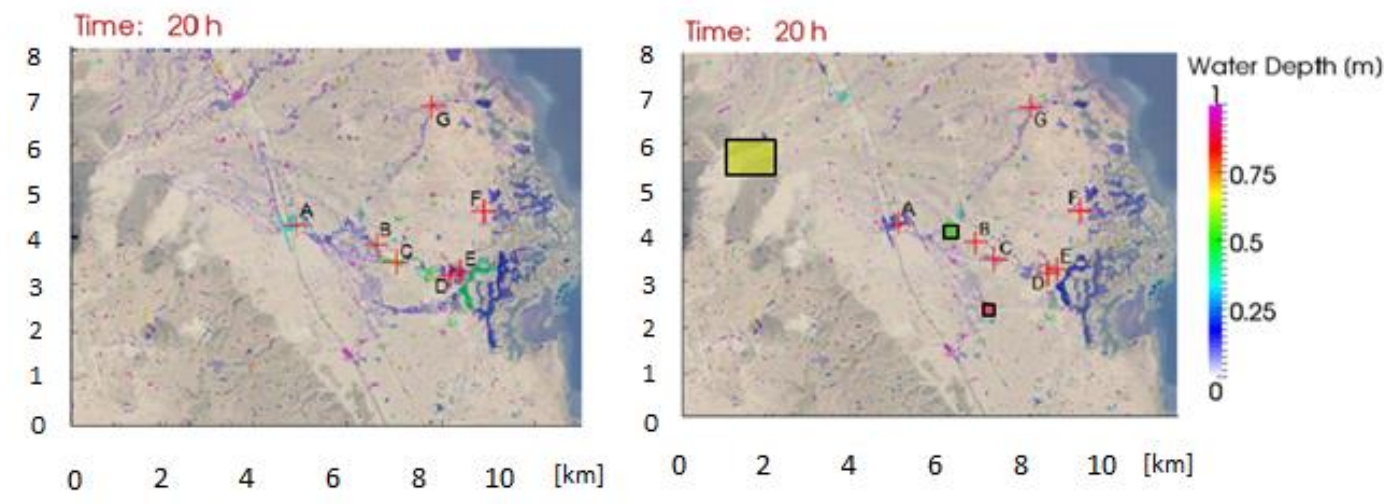

Figure 5: Water depths after 20h with no protection (left), with a large basin and 2 little basins as protection (right)

For points A, B, C, E, protection measures seem to work very well. As shown in Figure 6, the peak of the water depth without any protection is reduced at each point when measures are adopted to protect the city. They are the points affected by the passage of the main flow.

On the other hand, points D, F, G show a different behavior, since they are located in the north-east zone, where they are not influenced neither by the main flow, nor by protection measures. In fact, no variation over time is observed among different scenarios. The common trend is the reaching of a 
constant value asymptotically. This means that they are located in natural depressions, so the water level rises reaching a constant value.

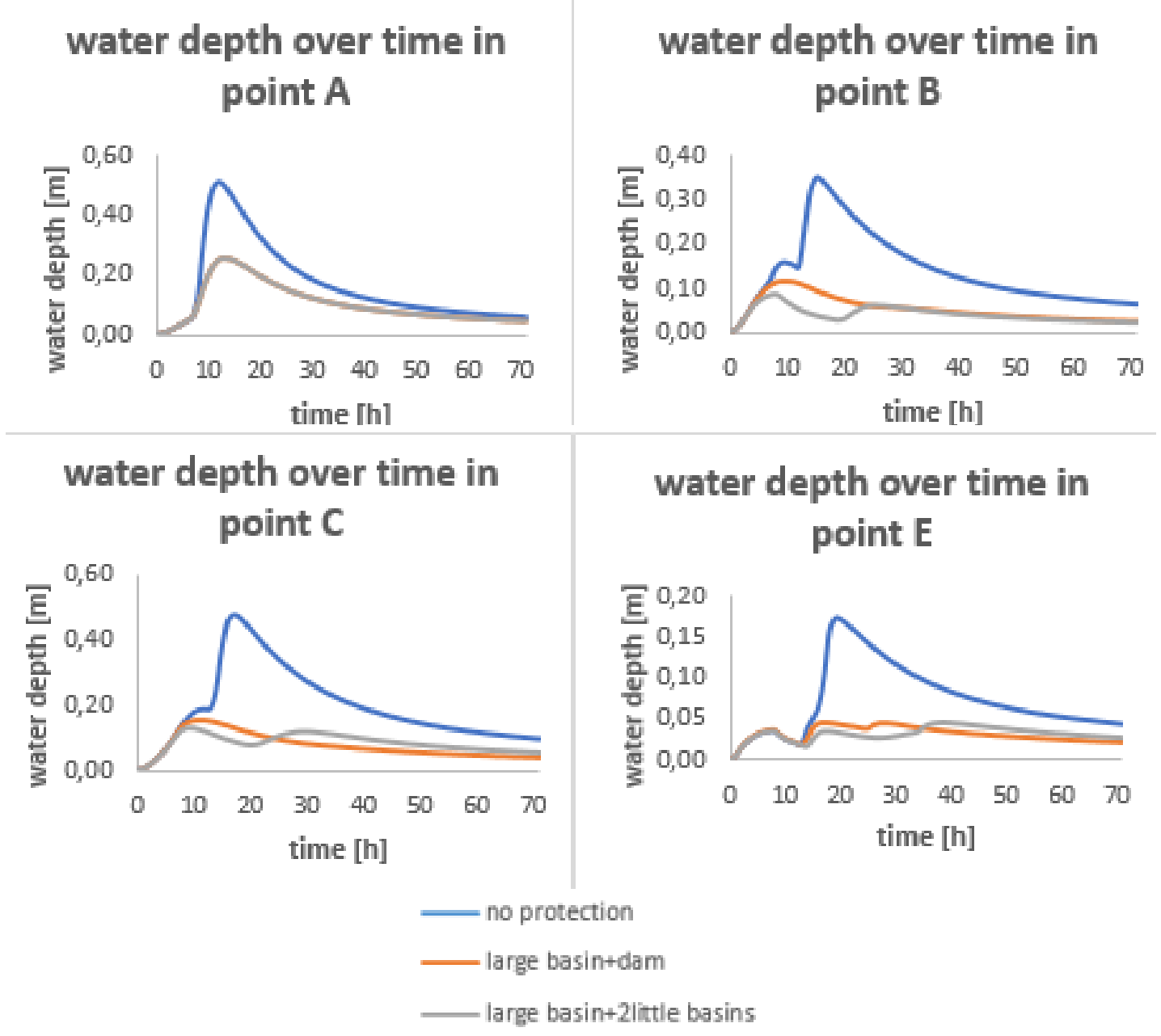

Figure 6: Water depth values for points A, B, C, E in case of three different scenarios simulated

\section{Conclusions}

In this study, the $9^{\text {th }}$ March 2014 flash flood event in El Gouna was simulated using a 2D shallow water model. An unstructured mesh and a Digital Elevation Model have been implemented into the model to represent the studied domain. Values of water depth have been written out at some strategical points nearby the buildings in flooding conditions and then compared for the cases with different protection measures and without using them. The scenario conceived with a large storage basin near the main inflow and two smaller basins has been proven to be the best approach to protect the city with 
inlets related to the simulated event. On the other hand, if a higher intensity event occurs, some overflow may represent a serious problem, strongly reducing efficiency in protection intent.

Hence, for further investigations, a new scenario would be conceived to face up to this problem, including a bypass system which connects the storage basins through a channel to the sea.

Moreover, in arid zones the influence of infiltration should be discussed for a flash flood event. In particular, implementing infiltration phenomenon in the model, still remains a central point in actual research studies. Very interesting results related to the study case are shown and discussed in Tügel's work (Tügel, et al., 2017).

\section{Aknowledgements}

In this work supercomputers of Norddeutscher Verbund für Hoch- und Höchstleistungsrechnen in Berlin, Germany were used to compute every simulation.

\section{References}

Busse, T., Simons, F., Mieth, S., Hinkelmann, R., \& Molkenthin, F. HMS: A generalised software design to enhance the modelling of geospatial referenced flow and transport phenomena. Hamburg: Proceedings of the 10th International Conference on Hydroinformatics - HIC 2012.

Hadidi, A. (2016). Wadi Bili Catchment in the Eastern Desert - Flash Floods, Geological Model and Hydrogeology. Berlin: Phd thesis Faculty VI - Planning Building Environment, Technische Universität.

Hou, J., Liang, Q., Simons, F., \& Hinkelmann, R. (2013). A stable 2D unstructured shallow flow model for simulations of wetting and drying over rough terrains. Computers \& Fluids, pp. 132-147.

Hou, J., Simons, F., \& Hinkelmann, R. (2013). A new TVD method for advection simulation on 2D unstructured grids. International Journal for Numerical Methods in Fluids, 10, 1260-1281.

Murillo, J., García-Navarro, P., \& Burguete, J. (2009). Conservative numerical simulation of multicomponent transport in two- dimensional unsteady shallow water flow. Journal of Computational Physics, 15(5539-5573).

Özgen, I., Simons, F., Zhao, J., \& Hinkelmann, R. (2014). Modeling Shallow Water Flow And Transport Processes With Small Water Depths Using The Hydroinformatics Modelling System. International Conference on Hydroinformatics CUNY Academic Works.

Simons, F., Busse, T., Hou, J., Özgen, I., \& Hinkelmann, R. (2012). HMS: Model Concepts and Numerical Methods around Shallow Water Flow within an Extendable Modeling Framework Understanding Changing Climate and Environment and Finding Solutions, Proceedings of the 10th International Conference on Hydroinformatics. Hamburg.

Simons, F., Busse, T., Hou, J., Özgen, I., \& Hinkelmann, R. (2014). A model for overland flow and associated processes within the Hydroinformatics Modelling System. Journal of Hydroinformatics, 16(2), 375-391.

Tügel, F., Marafini, E., Özgen, H. A., La Rocca, M., Tröger, U., \& Hinkelmann, R. (2017). Flash flood simulations considering infiltration processes and structural protection measures for El Gouna, Egypt. Muscat: 3rd International Symposium on Flash Floods in Wadi Systems.

Tügel, F., Özgen, I., Simons, F., Zhao, J., \& Hinkelmann, R. (2017). Modelling of Flash Floods in Wadi Systems Using a Robust Shallow Water Model - Case Study El Gouna, Egypt. Nice: SimHydro Conference. 